\title{
Produção do feijão-caupi cultivado em sucessão ao consórcio entre milho e Urochloa
}

\section{ruziziensis}

\author{
Production of caupi bean cultivated in succession to the consortium between corn and Urochloa \\ ruziziensis
}

Producción de caupi cultivada en sucesión al consorcio entre maíz y Urochloa ruziziensis

Recebido: 24/01/2021 | Revisado: 01/02/2021 | Aceito: 02/02/2021 | Publicado: 08/02/2021

\author{
Fernanda Pereira Marques \\ ORCID: https://orcid.org/0000-0002-0251-8642 \\ Instituto Federal de Educação, Ciência e Tecnologia Goiano, Brasil \\ E-mail: ferdsmarques@hotmail.com \\ Letícia Carvalho dal' Evedove \\ ORCID: https://orcid.org/0000-0003-2553-2364 \\ Instituto Federal de Educação, Ciência e Tecnologia Goiano, Brasil \\ E-mail: leticiarvd2010@gmail.com \\ Victor Garcia Leão \\ ORCID: https://orcid.org/0000-0002-4663-096X \\ Instituto Federal de Educação, Ciência e Tecnologia Goiano, Brasil \\ E-mail: victorgarcialeao@hotmail.com \\ Jaqueline Oliveira da Silva \\ ORCID: https://orcid.org/0000-0002-6655-2700 \\ Instituto Federal de Educação, Ciência e Tecnologia Goiano, Brasil \\ E-mail: jaqueline_16@outlook.com.br \\ Carlos Henrique de Lima e Silva \\ ORCID: 0000-0001-5173-5224 \\ Instituto Federal de Educação, Ciência e Tecnologia Goiano, Brasil \\ E-mail: valadares_ufsj@yahoo.com.br \\ Jeovane Nascimento Silva \\ ORCID: 0000-0002-1415-1825 \\ Instituto Federal de Educação, Ciência e Tecnologia Goiano, Brasil \\ E-mail: jeovaneagro@gmail.com \\ Adriano Jakelaitis \\ ORCID: https://orcid.org/0000-0003-0093-9846 \\ Instituto Federal de Educação, Ciência e Tecnologia Goiano, Brasil \\ E-mail: adriano.jakelaitis@ifgoiano.edu.br
}

\begin{abstract}
Resumo
O consórcio da cultura do milho com Urochloa ruziziensis tem sido amplamente utilizado visando a formação de palhada e a supressão de plantas daninhas. Neste trabalho, objetivou-se avaliar os efeitos da densidade de semeadura de $U$. ruziziensis em consórcio com milho tratado ou não com subdose de glifosato e o desempenho da cultura do feijão-caupi cultivado em sucessão. O delineamento usado foi o de blocos ao acaso, com quatro repetições. No consórcio entre o milho e a forrageira foi adotado o esquema fatorial $2 \times 3+1$, sendo que o primeiro fator constou da aplicação ou não do herbicida glifosato $\left(55 \mathrm{~g} \mathrm{ha}^{-1}\right)$ e o segundo fator das taxas de semeadura da forrageira $(10,12,5 \mathrm{e}$ $15 \mathrm{~kg} \mathrm{ha}^{-1}$ ), mais o monocultivo de milho. Para a cultura do feijão-caupi cultivado em sucessão foram testadas as palhadas oriundas do consórcio, alocadas nas parcelas, e nas subparcelas a aplicação ou não dos herbicidas imazamoxi + bentazon + fluazifope-p-butilico em pós-emergência. O sistema de consórcio, independente das taxas de semeadura da $U$. ruziziensis ou do seu manejo com glifosato, contribui para a redução da infestação de plantas daninhas. $\mathrm{O}$ uso de glifosato reduziu a produção de palhada de $U$. ruziziensis no momento da colheita do milho. Porém, as palhadas produzidas pelos consórcios, independente dos tratamentos, não contribuiu com o controle de plantas daninhas principalmente de propagação vegetativa. A produção de grãos das culturas de milho e de feijão-caupi não foram afetadas pelos tratamentos testados.
\end{abstract}

Palavras-chave: Sistemas integrados; Zea mays; Urochloa ruziziensis; Vigna unguiculata.

\section{Abstract}

The intercropping of corn with Urochloa ruziziensis has been widely used for straw formation and weed suppression. In this work, the objective was to evaluate the effects of $U$. ruziziensis sowing density in intercropping with corn treated or not with glyphosate subdose as well as the performance of cowpea crop grown in succession. The design used was randomized blocks, with four replications. In an intercropping between corn and forage, the factorial scheme 
$2 \times 3+1$ was adopted, the first factor being the application or not of the herbicide glyphosate $\left(55 \mathrm{~g} \mathrm{ha}^{-1}\right)$ and the second factor was forage sowing rates $\left(10,12.5\right.$ and $\left.15 \mathrm{~kg} \mathrm{ha}^{-1}\right)$, plus corn monoculture. For cowpea grown cultivation in succession, the straws from the intercropping were tested, allocated in the plots, and in the subplots the application or not of the herbicides imazamoxi + bentazon + fluazifop-p-butil in post-emergence. The intercropping system, regardless of $U$. ruziziensis sowing rates or glyphosate management, contributes to reducing weed infestation. The use of glyphosate reduced the production of $U$. ruziziensis straw at the time of corn harvest. However, the straw produced by the intercropping, regardless of treatments, did not contribute to the weeds control in the cowpea culture. The corn grain production and cowpea crops were not affected by the treatments tested.

Keywords: Integrated systems; Zea mays; Urochloa ruziziensis; Vigna unguiculata.

\section{Resumen}

El cultivo intercalado de maíz con Urochloa ruziziensis se ha utilizado ampliamente para la formación de paja y la supresión de malezas. En este trabajo, el objetivo fue evaluar los efectos de la densidad de siembra de $U$. ruziziensis en cultivos intercalados con maíz tratado o no con subdosis de glifosato, así como el comportamiento del cultivo de caupí cultivado en sucesión. El diseño utilizado fue de bloques al azar, con cuatro repeticiones. En un cultivo intercalado entre maíz y forrajes se adoptó el esquema factorial $2 \times 3+1$, siendo el primer factor la aplicación o no del herbicida glifosato $\left(55 \mathrm{~g} \mathrm{ha}^{-1}\right)$ y el segundo factor las tasas de siembra de forrajes $\left(10,12,5 \mathrm{y} 15 \mathrm{~kg} \mathrm{ha}^{-1}\right)$, más monocultivo de maíz. Para el cultivo sucesivo de caupí, se probaron las pajas del intercalado, se distribuyeron en las parcelas y en las subparcelas la aplicación o no de los herbicidas imazamoxi + bentazon + fluazifop-p-butilico en post-emergencia. El sistema de cultivos intercalados, independientemente de las tasas de siembra de U. ruziziensis o del manejo del glifosato, contribuye a reducir la infestación de malezas. El uso de glifosato redujo la producción de paja de $U$. ruziziensis en el momento de la cosecha del maíz. Sin embargo, la paja producida por el cultivo intercalado, independientemente de los tratamientos, no contribuyó al control de malezas en el cultivo de caupí. La producción de granos de maíz y los cultivos de caupí no se vieron afectados por los tratamientos probados.

Palabras clave: Sistemas integrados; Zea mays; Urochloa ruziziensis; Vigna unguiculata.

\section{Introdução}

O estado de Goiás tem sido um importante colaborador na produção de grãos no cenário nacional. Na safra 2019/20, cultivou a área de 1,52 milhões de hectares para a cultura do milho, aproximadamente 10,15 milhões de toneladas desse cereal (Conab, 2020). A expansão dessa cultura no estado tem ocorrido pelas condições favoráveis, além da possibilidade de bons rendimentos.

Um dos fatores limitantes para a elevação da produtividade das culturas agrícolas é o manejo adequado de plantas daninhas (Grazziero, et al., 2019; Krenchinski, et al., 2019). Principalmente após a inserção de plantas geneticamente modificadas, em que o controle químico de plantas daninhas é realizado quase que exclusivamente pelo herbicida glifosato (Mechi, et al., 2018).

A adoção de um sistema que integra a produção agrícola com a pecuária (ILP), está sendo considerada como forma de melhorar a sustentabilidade, produzindo mais alimentos (Lemaire, et al., 2014). O sistema de produção em forma de consórcio consiste na produção de duas ou mais espécies vegetais de interesse econômico que são cultivadas numa mesma área de forma simultânea (Araújo, et al., 2018). E, o cultivo do milho com espécies forrageiras do gênero Urochloa spp. tem sido uma das alternativas (Pariz, et al., 2017).

Os benefícios do sistema ILP incluem o aumento da fertilidade do solo, pelo acúmulo de matéria orgânica, melhoria na ciclagem de nutrientes e melhor agregação do solo (Silva, et al, 2018). Além disso, o sistema ILP tem sido adotado como alternativa para a redução da comunidade infestante de plantas daninhas de difícil controle (Mechi, et al., 2018). Ademais, diminui o uso de herbicidas de forma considerável, reduzindo os custos de produção e causando menos impactos ambientais (Martha Junior, et al., 2011).

Com a melhoria da cobertura do solo, consequentemente ocorre a redução da comunidade infestante, aumentando a produtividade da cultura sucessora, maior produtividade de grãos e forragem, além da diversificação da produção (Chioderoli, et al., 2010). Dentre as principais limitações nos sistemas consorciados estão a forma e época de semeadura das espécies consortes, competição da forrageira com a cultura do milho e a utilização de herbicidas (Moraes, et al., 2014). 
O Estado de Goiás também tem se projetado nos últimos anos como importante produtor de feijão-caupi. De acordo com Silva et al. (2015), a expansão da cultura tem ocorrido no Cerrado em condições de safrinha, principalmente pela precocidade da cultura e a tolerância ao déficit hídrico em relação a outros cultivos como milho, além da adaptação ao cultivo mecanizado. Segundo os autores, o baixo custo e a possibilidade de bons rendimentos são os principais atrativos para o cultivo desta leguminosa.

Atualmente, inexistem estatísticas oficiais sobre a produção de feijão-caupi, à exceção de alguns estados (Conab, 2019). Contudo, Silva et al. (2011) apontam que as estimativas indicam a inexistência de produção de feijão-caupi nos estados do Acre, Distrito Federal, Goiás, Mato Grosso do Sul, Minas Gerais, São Paulo e Tocantins, quando, de fato, sabe-se da existência de produção de feijão-caupi nestes estados.

O município de Rio Verde tem importante participação na produção de grãos, uma vez que produz soja geneticamente modificada para resistência ao glifosato (GMRG) na safra e milho GMRG na safrinha e ambas são culturas importantes para o Estado no cenário nacional e para a região do sudoeste goiano em particular. Quanto à produção de feijão-caupi, a região do sudoeste goiano é promissora para sua produção em decorrência da topografia favorável a mecanização, das áreas cultivadas com outras grandes culturas e da distribuição de chuvas no período de safrinha.

Neste trabalho, objetivou-se avaliar os efeitos da densidade de semeadura de U. ruziziensis em consórcio com milho tratado ou não com subdose de glifosato e o desempenho da cultura do feijão-caupi cultivado em sucessão.

\section{Metodologia}

A cultura do milho foi conduzida em campo em Rio Verde ( $17^{\circ} 48^{\prime}$ e $67^{\prime \prime} \mathrm{S}$ e $50^{\circ} 54^{\prime} 18^{\prime \prime} \mathrm{W}$ e altitude de $\left.754 \mathrm{~m}\right)$, GO, durante a safra 2019/20. O solo da área, caracterizado como Latossolo Vermelho distroférrico, apresentou na profundidade de 0 a $20 \mathrm{~cm}$, a seguinte composição físico-química: pH 6,2 (SMP), Ca 4,64 $\mathrm{cmol}_{\mathrm{c}} \mathrm{dm}^{-3}, \mathrm{Mg} 2,50 \mathrm{cmol}_{\mathrm{c}} \mathrm{dm}^{-3}, \mathrm{Al} 3+0,04 \mathrm{cmol}_{\mathrm{c}}$ $\mathrm{dm}^{-3}, \mathrm{H}+\mathrm{Al}$ 4,5 $\mathrm{cmol}_{\mathrm{c}} \mathrm{dm}^{-3}$, CTC 12,1 $\mathrm{cmol}_{\mathrm{c}} \mathrm{dm}^{-3}$ e K 0,46 $\mathrm{cmol}_{\mathrm{c}} \mathrm{dm}^{-3}$ e P (Melich) 13,1 $\mathrm{mg} \mathrm{dm}^{-3}$, matéria orgânica 3,62 mg $\mathrm{dm}^{-3}$ e $\mathrm{Zn} \mathrm{4,5} \mathrm{mg} \mathrm{dm}^{-3}$, saturação por bases $62,8 \%$, saturação por alumínio $0,5 \%$, argila $64,5 \%$, silte $10,0 \%$ e areia $25,5 \%$. Antes da instalação do ensaio, a vegetação do local foi dessecada com o herbicida glifosato (Glifosato Nortox® 480 SL) na dose de $2400 \mathrm{~g} \mathrm{ha}^{-1}$ e quinze dias após foi feito o preparo do solo por meio de aração e gradagens.

Nesta pesquisa de natureza quantitativa (Pereira, et al., 2018), o delineamento experimental utilizado foi em blocos ao acaso, com quatro repetições. Os tratamentos foram arranjados em esquema fatorial $2 \times 3+1$, com quatro repetições, sendo o primeiro fator a aplicação ou não da dose do herbicida e o segundo fator as densidades de semeadura da forrageira Urochloa ruziziensis $\left(10,12,5\right.$ e $\left.15 \mathrm{~kg} \mathrm{ha}^{-1}\right)$. O tratamento adicional foi constituído pelo monocultivo do milho. As parcelas experimentais foram constituídas de dez linhas de milho com dez metros de comprimento. A área útil de cada parcela foi constituída de $15,00 \mathrm{~m}^{2}$, nas quais foram avaliadas seis linhas centrais.

O híbrido FS500PW de milho foi semeado no dia 21 de outubro de 2019, com uso de semeadora múltipla de cinco linhas de plantio no espaçamento de $0,45 \mathrm{~m}$ entre linhas e 3,2 sementes $\mathrm{m}^{-1}$. Na mesma data de plantio foi realizada a semeadura da $U$. ruziziensis de forma manual a lanço, conforme as especificações de cada tratamento.

Aos 20 dias após a emergência (DAE) do milho nos tratamentos que continham glifosato foi realizada a aplicação na dose de $55 \mathrm{~g} \mathrm{ha}^{-1}+1.500 \mathrm{~g} \mathrm{ha}^{-1}$ de atrazina (Atrazina Nortox ${ }^{\circledR} 500 \mathrm{SC}$ ), e nas demais parcelas do consórcio apenas foi aplicado atrazina na dose de $1.500 \mathrm{~g} \mathrm{ha}^{-1}$. No monocultivo de milho foi aplicado $1.500 \mathrm{~g} \mathrm{ha}^{-1}$ de atrazina $+960 \mathrm{~g} \mathrm{ha}^{-1} \mathrm{de}$ glifosato. A aplicação foi realizada com pulverizador costal pressurizado com $\mathrm{CO}_{2}$, mantendo a pressão constante de 2 bar, com a barra equipada com bicos TT110.02, espaçados de $0,50 \mathrm{~m}$ e calibrados para aplicar o equivalente a $250 \mathrm{~L} \mathrm{ha}^{-1}$ de calda.

Aos 25 DAE do milho foi realizada a aplicação de $150 \mathrm{~g} \mathrm{ha}^{-1}$ de benzoato de emamectina (Proclaim® 50) para o controle de Spodoptera frugiperda e após 15 dias realizou as aplicações de $12,5 \mathrm{~g}$ de beta-ciflutrina $+100 \mathrm{~g}$ de imidacloprid 
(Connect®) para o controle do mesmo inseto-praga e de $60 \mathrm{~g}$ de trifloxistrobina $+120 \mathrm{~g}$ de tebuconazol (Nativo®) para Puccinia polysora e Phaeosphaeria maydis. No dia 22 de dezembro de 2019 foi realizada a aplicação de $200 \mathrm{~kg}^{-1} \mathrm{de}^{-1}$ ureia (45\%) e $120 \mathrm{~kg} \mathrm{ha}^{-1} \mathrm{de} \mathrm{KCl.}$

Aos 60, 90 e 120 DAE do milho foram realizadas a determinação de massa seca de $U$. ruziziensis e densidade de plantas daninhas. As plantas foram obtidas de duas amostras de 1,0 $\mathrm{m}^{2}$ coletadas ao acaso na parcela por meio do lançamento de um quadrado metálico vazado. Em cada época de avaliação, o material foi amostrado, acondicionado em sacos de papel e secos em estufa com ventilação forçada a $70^{\circ} \mathrm{C}$ por 72 horas até atingir massa constante. Semelhantemente, foram coletadas as plantas daninhas nas amostras de $0,25 \mathrm{~m}^{2}$, as quais foram separadas por espécies, contadas e determinada a massa seca.

No milho aos 90 DAE foi determinada a altura de plantas, altura de espigas, diâmetro do colmo e massa seca total da parte aérea. Na ocasião da colheita de grãos, aos 120 dias após a emergência, na área útil das parcelas foram realizadas avaliações de número de plantas e determinação do rendimento de grãos. Da massa de grãos foi determinada a massa de cem grãos, com umidade corrigida para $13 \%$.

Vinte dias após a colheita do milho, a vegetação foi dessecada com glifosato na dose de $1440 \mathrm{~g} \mathrm{ha}^{-1}$ e em 14/03/2020 foi semeado o feijão-caupi BRS Tumucumaque sobre a palhada remanescente. A semeadura do feijão foi realizada com o auxílio de uma semeadora múltipla de cinco linhas, espaçadas com $0,45 \mathrm{~m}$ entrelinhas e população de 15 sementes por $\mathrm{m}^{-1}$. As sementes de feijão foram tratadas com Standak® Top na dose de $200 \mathrm{~mL}$ do produto comercial para $100 \mathrm{~kg}$ de sementes. A adubação de semeadura foi de $150 \mathrm{~kg} \mathrm{ha}^{-1}$ da formulação 04-30-16 de NPK.

Os tratamentos no feijoeiro foram arranjados na mesma estrutura anterior com as parcelas subdivididas, que corresponderam nas parcelas as palhadas para semeadura direta, obtidas dos cultivos do consórcio entre o milho e a forrageira e do monocultivo de milho e nas subparcelas constaram da ausência e da aplicação de herbicidas em pós-emergência do feijãocaupi. O delineamento usado foi de blocos ao acaso com quatro repetições. Em 08/04/2020 foi aplicado a mistura pronta dos herbicidas bentazona + imazamoxi (Amplo®) nas doses $600+28 \mathrm{~g} \mathrm{ha}^{-1}$, respetivamente, e cinco dias após foi feita a aplicação de fluazifope-p-butílico (Fusilade ${ }^{\circledR} 250 \mathrm{EW}$ ) na $187,5 \mathrm{~g} \mathrm{ha}^{-1} \mathrm{~A}$ aplicação foi realizada com pulverizador costal pressurizado com $\mathrm{CO} 2$, mantendo a pressão constante de 2 bar, com barra equipada com bicos TT110.02, espaçados de 0,50 m e calibrados para aplicar o equivalente a $210 \mathrm{~L} \mathrm{ha}^{-1}$ de calda.

As avaliações de plantas daninhas foram feitas aos 15 dias após a aplicação do herbicida fluazifope-p-butílico e na colheita do feijão-caupi aos 68 DAE. As plantas daninhas foram colhidas de duas amostras de $0,25 \mathrm{~m}^{2}$ ao acaso na subparcela por meio do lançamento de um quadrado metálico vazado. Em cada época de avaliação, as plantas foram identificadas, contadas e o material foi separado e acondicionado em sacos de papel e secos em estufa com ventilação forçada a $70^{\circ} \mathrm{C}$ por 72 horas até atingir massa constante.

Na colheita do feijão foram avaliados a população de plantas e o rendimento de grãos na área útil de cada subparcela. O número de vagens por planta e de grãos por planta foi determinado pela contagem de cinco plantas por subparcela e a massa de cem grãos foi determinada, em triplicata.

Os dados foram submetidos à análise de variância pelo teste $\mathrm{F}$ e, em caso de significância, submetidos ao teste de Tukey para comparações de médias entre os níveis dos fatores e ao teste de Dunnett para comparar com o tratamento adicional. O nível de significância adotado foi de 5\%. As variáveis massa seca de braquiária (MSB), densidade (DE) e massa seca de plantas daninhas (MSPD) foram transformadas $(x+0,5)^{0,5}$.

\section{Resultados e Discussão}

As principais plantas daninhas que ocorreram no consórcio entre milho e U. ruziziensis e no monocultivo de milho foram Alternanthera tenella (apaga-fogo), Panicum maximum (capim-colonião), Digitaria insularis (capim-amargoso), 
Amaranthus spinosus (caruru), Nicandra physaloides (joa-de-capote), Euphorbia heterophylla (leiteiro), Ageratum conyzoides (mentrasto), Eleusine indica (capim-pé-de-galinha), Cyperus spp (tiririca) e Commelina benghalensis (trapoeraba). Para a densidade e a produção de massa seca de PD não foram observadas interações significativas entre as taxas de semeadura de $U$. ruziziensis e a aplicação de glifosato no consórcio entre milho e a forrageira nas avaliações feitas aos 60, 90 e 120 DAE (Tabela 1).

Por outro lado, em relação ao monocultivo de milho as densidades de plantas daninhas em todas as épocas avaliadas e a massa seca aos 90 e 120 DAE apresentaram resultados menores, demonstrando que a comunidade infestante foi suprimida pelo estabelecimento do consórcio do milho com a forrageira U. ruziziensis. Independente das taxas de semeadura da forrageira em consórcio e do manejo com glifosato, o consórcio do milho e da forrageira favoreceu o controle de plantas daninhas exercendo redução da infestação das plantas daninhas na área.

Tabela 1. Densidade (DE) e massa seca (MS) de plantas daninhas, em função dos tratamentos, avaliados aos 60, 90 e 120 dias após a emergência do milho (DAE).

\begin{tabular}{|c|c|c|c|c|c|c|c|}
\hline \multirow{3}{*}{ Taxa de semeadura } & \multirow{3}{*}{ Glifosato } & \multicolumn{3}{|c|}{$\mathrm{DE}\left(\mathrm{n} \mathrm{m}^{-2}\right)$} & \multicolumn{3}{|c|}{$\mathrm{MS}\left(\mathrm{g} \mathrm{m}^{-2}\right)$} \\
\hline & & \multicolumn{3}{|c|}{ Dias após a emergência } & \multicolumn{3}{|c|}{ Dias após a emergência } \\
\hline & & 60 & 90 & 120 & 60 & 90 & 120 \\
\hline \multirow{2}{*}{$10 \mathrm{~kg} \mathrm{ha}^{-1}$} & Sem & $15,50^{1}-$ & $3,00-$ & 1,75 & $2,82^{\text {ns }}$ & $2,23-$ & $11,14-$ \\
\hline & Com & $11,00-$ & $2,00-$ & $1,25-$ & 4,46 & $0,84-$ & $4,18-$ \\
\hline \multirow{2}{*}{$12,5 \mathrm{~kg} \mathrm{ha}^{-1}$} & Sem & $24,50-$ & $1,50-$ & $1,00-$ & 5,18 & $1,80-$ & $9,01-$ \\
\hline & Com & $11,00-$ & $0,50-$ & $0,50-$ & 3,52 & $1,56-$ & $7,78-$ \\
\hline \multirow{2}{*}{$15 \mathrm{~kg} \mathrm{ha}^{-1}$} & Sem & $8,50-$ & $1,00-$ & $0,50-$ & 7,22 & $1,13-$ & $5,66-$ \\
\hline & Com & $7,00-$ & $0,00-$ & $0,00-$ & 4,55 & $0,00-$ & $0,00-$ \\
\hline \multicolumn{2}{|c|}{ Monocultivo de milho } & 81,50 & 40,50 & 21,25 & 1,17 & 7,30 & 36,48 \\
\hline \multicolumn{2}{|c|}{$\mathrm{CV}(\%)$} & 58,14 & 66,19 & 29,33 & 57,89 & 93,85 & 15,76 \\
\hline
\end{tabular}

ns - não significativo pelo teste $\mathrm{F}(\mathrm{p}>0,05)$. ${ }^{1}$ Médias acompanhadas do sinal (-) são estatisticamente inferiores à média do monocultivo de milho pelo teste de Dunett $(\mathrm{p}<0,05)$. Os valores de densidade e massa seca foram transformados em $(\mathrm{x}+0,5)^{0,5}$ para análise.

Fonte: Autores (2021).

Para a massa seca de U. ruziziensis avaliada aos 60, 90 e 120 DAE não foi observada interação entre fatores, apenas efeito da aplicação de glifosato sobre as plantas avaliadas na colheita do milho (120 DAE) (Tabela 2). Não houve incremento das taxas de semeadura na produção de massa seca da forrageira e esta foi pouco expressiva até aos 90 DAE. Nos 120 DAE na colheita do milho, observou-se maior incremento de massa seca, e está relacionado com a maior incidência luminosa pelo dossel do milho, atingindo acima de $127 \mathrm{~g} \mathrm{~m}^{-2}$ na menor taxa de semeadura. Esses dados corroboram os resultados de Portes et al. (2000), que obteve produção de massa seca total de Urochloa a cerca de $2.300 \mathrm{~kg} \mathrm{ha}^{-1}$ no período de colheita do milho.

Quando submetidas ao sombreamento, as plantas de braquiária apresentam crescimento lento (Portes, et al., 2000), e à medida que ocorre aumento da radiação solar no dossel forrageiro pela senescência do milho ela apresenta aumento no acúmulo de massa seca. Este efeito se torna evidente com a resposta da aplicação do glifosato, em que a produção de massa seca da braquiária tratada e não tratada não diferem entre si nas avaliações feitas aos 60 e 90 DAE e, tornam-se contrastantes aos $120 \mathrm{DAE}$, em que a forrageira não afetada pelo glifosato manifesta maior acúmulo de massa seca. Segundo Silva et al. (2004), a utilização de herbicidas seletivos à cultura produtora de grãos no consórcio favorece esta cultura, e se houver efeitos fitotóxicos sobre a forrageira, seu rendimento de massa seca fica reduzido. A seletividade de herbicidas para as gramíneas forrageiras depende da espécie, do estágio de desenvolvimento, da molécula do herbicida e da finalidade do consórcio (Martins, et al. 2007). 
Tabela 2. Massa seca (MS) de Urochloa ruziziensis avaliadas aos 60, 90 e 120 dias após a emergência (DAE) do milho em função dos tratamentos.

\begin{tabular}{cccc}
\hline \multirow{2}{*}{ Tratamentos } & \multicolumn{3}{c}{ MS $\left(\mathrm{g} \mathrm{m}^{-2}\right)$} \\
\cline { 2 - 4 } & \multicolumn{3}{c}{ Dias após a emergência do milho } \\
\hline Taxa de semeadura & $52,67^{\text {ns }}$ & $70,59^{\text {ns }}$ & 120 \\
\hline $10 \mathrm{~kg} \mathrm{ha}^{-1}$ & 54,02 & 67,96 & $158,50^{\text {ns }}$ \\
$12,5 \mathrm{~kg} \mathrm{ha}^{-1}$ & 52,77 & 73,23 & 182,63 \\
$15 \mathrm{~kg} \mathrm{ha}^{-1}$ & & & $207,00^{1} \mathrm{a}$ \\
\hline Glifosato & $52,75^{\text {ns }}$ & $67,20^{\text {ns }}$ & $105,25 \mathrm{~b}$ \\
\hline Sem & 53,56 & 73,98 & 19,83 \\
\hline Com & 15,17 & 7,49 &
\end{tabular}

ns - não significativo pelo teste $\mathrm{F}(\mathrm{p}>0,05) .{ }^{1}$ Médias seguidas pelas mesmas letras são estatisticamente iguais pelo teste $\mathrm{F}$ ( $\left.\mathrm{p}>0,05\right)$. Fonte: Autores (2021).

As variáveis avaliadas no milho altura de plantas e de inserção de espiga, massa seca total, produção de grãos, e massa de cem grãos não foram constatadas diferenças estatísticas, concluindo pela ausência de interferência da $U$. ruzizizensis nas características produtivas do milho, isto é, não houve competição entre as plantas capaz de reduzir a produção de grãos (Tabela 3). A competição entre as espécies componentes da comunidade de plantas somente acontece quando a demanda dos competidores pelos recursos do meio ultrapassa a capacidade do meio de fornecer estes recursos ou quando um dos competidores impede o acesso do recurso ao outro (Gimenes, et al., 2011).

Assim, pode-se afirmar que nas taxas de semeadura empregado U. ruziziensis não interferiu nos componentes de produção da cultura do milho. Vale ressaltar que a aplicação de glifosato para reduzir a taxa de crescimento da forrageira, apesar de não afetar os componentes de produção do milho, pode ser uma alternativa para reduzir a biomassa da forrageira no período de colheita, e facilitaria a operação de colheita de grãos. Estes resultados corroboram com os observados por Chioderoli et al. (2012), que mostraram que o consórcio de milho com Urochloa não acarretou efeito negativo na produtividade de milho.

Tabela 3. Altura de plantas (AP), altura de espigas (AE), diâmetro de colmo (DC), massa seca da parte aérea (MST) de plantas de milho, rendimento de grãos (RG) e massa de cem grãos (MCG) de milho em função das taxas de semeadura e da aplicação de glifosato.

\begin{tabular}{|c|c|c|c|c|c|c|c|}
\hline \multirow{2}{*}{ Taxa de semeadura } & \multirow{2}{*}{ Glifosato } & $\mathrm{AP}$ & $\mathrm{AE}$ & \multirow{2}{*}{$\begin{array}{c}\mathrm{DC} \\
\mathrm{mm} \\
\end{array}$} & MST & $\mathrm{RG}$ & \multirow{2}{*}{$\begin{array}{c}\mathrm{MCG} \\
\mathrm{g}\end{array}$} \\
\hline & & \multicolumn{2}{|c|}{$\mathrm{cm}$} & & \multicolumn{2}{|c|}{$\mathrm{kg} \mathrm{ha}^{-1}$} & \\
\hline \multirow{2}{*}{$10 \mathrm{~kg} \mathrm{ha}^{-1}$} & Sem & $2,38^{\text {ns }}$ & $1,39^{\text {ns }}$ & $25,20^{\mathrm{ns}}$ & $15.439,87^{\mathrm{ns}}$ & $8.208,00^{\text {ns }}$ & $32,01^{\mathrm{ns}}$ \\
\hline & Com & 2,40 & 1,35 & 25,42 & $15.603,75$ & $8.100,60$ & 32,42 \\
\hline \multirow{2}{*}{$12,5 \mathrm{~kg} \mathrm{ha}^{-1}$} & Sem & 2,39 & 1,33 & 24,34 & $14.403,54$ & $7.351,80$ & 32,01 \\
\hline & Com & 2,47 & 1,35 & 25,22 & $16.259,02$ & $8.425,20$ & 32,94 \\
\hline \multirow{2}{*}{$12,5 \mathrm{~kg} \mathrm{ha}^{-1}$} & Sem & 2,42 & 1,38 & 23,24 & $14.921,31$ & $7.798,80$ & 30,93 \\
\hline & Com & 2,44 & 1,39 & 25,58 & $13.980,67$ & $7.764,00$ & 32,27 \\
\hline Monocultivo de milho & & 2,39 & 1,37 & 25,38 & $17.163,35$ & $8.593,20$ & 32,72 \\
\hline $\mathrm{CV}(\%)$ & & 2,26 & 2,83 & 5,14 & 19,63 & 11,91 & 6,67 \\
\hline
\end{tabular}

ns - não significativo pelo teste $\mathrm{F}(\mathrm{p}>0,05)$.

Fonte: Autores (2021). 
Devido a maior presença de espécies de plantas daninhas de difícil controle e de propagação vegetativa não foi observado contribuição da palhada remanescente do consórcio no controle de plantas daninhas na cultura do feijão-caupi estabelecido em sucessão (Tabela 4). Nota-se que para a comunidade infestante estabelecida na cultura do feijão-caupi foi necessária a intervenção com o controle químico feito com latifolicidas (bentazon + imazamoxi) e graminicida (fluazifope-pbutílico) aplicado em pós-emergência da cultura para o controle de plantas daninhas (Tabela 4).

A comunidade infestante na cultura do feijão foi composta principalmente por A. tenella, E. heterophylla, Argemone mexicana (papoula do México), Zea mays (milho tiguera), P. maximum, A. spinosum, Bidens pilosa (picão-preto), $C$. benghalensis, A. conyzoides, Cyperus spp., Conyza spp. (buva), Richardia brasiliensis (poaia) e Portulaca oleracea (beldroega). Muitas destas espécies se estabelecem de propágulos vegetativos como C. benghalensis e Cyperus ou possuem sementes graúdas (milho tiguera, leiteiro, papoula-do-México, picão-preto) com quantidade significativa de reservas, as quais a quantidade e distribuição de palhadas resultantes dos tratamentos consorciados não foram suficientes para promover impedimento à germinação.

Para as variáveis relacionadas ao feijão-caupi os números de vagens e de grãos por planta, massa de cem grãos e de rendimento de grãos não foram observadas interação significativa entre palhadas remanescentes do consórcio e aplicação de herbicidas em pós-emergência do feijão. A eficiência do controle químico de plantas daninhas e a manutenção do rendimento de grãos do feijão-caupi com o uso dos herbicidas (bentazon + imazamoxi) + fluazifope são relatadas por Silva et al. (2014) e por Mesquita et al. (2017).

Tabela 4. Densidade (DE) e massa seca (MS) de plantas daninhas e número de vagens por planta (NVP), número de grãos por planta (NGP), massa de cem grãos (MCG) e rendimento de grãos (RG) do feijão-caupi em função da palhada remanescente do consórcio e do monocultivo de milho e da aplicação de herbicidas em pós-emergência do feijoeiro.

\begin{tabular}{|c|c|c|c|c|c|c|c|c|c|}
\hline \multirow{2}{*}{$\begin{array}{c}\text { Palhadas } \\
\text { remanescentes }\end{array}$} & \multirow{2}{*}{ Herbicida } & $\mathrm{DS}^{\mathrm{a} /}$ & $\mathrm{MST}^{\mathrm{a} /}$ & $\mathrm{DS}^{\mathrm{b} /}$ & $\mathrm{MST}^{\mathrm{b} /}$ & \multirow{2}{*}{ NVP } & \multirow{2}{*}{ NGP } & \multirow{2}{*}{$\frac{\mathrm{MCG}}{\mathrm{g}}$} & \multirow{2}{*}{$\begin{array}{c}\mathrm{RG} \\
\mathrm{kg} \mathrm{ha}^{-1}\end{array}$} \\
\hline & & $\mathrm{n} \mathrm{m}^{-2}$ & $\mathrm{~g} \mathrm{~m}^{-2}$ & $\mathrm{n} \mathrm{m}^{-2}$ & $\mathrm{~g} \mathrm{~m}^{-2}$ & & & & \\
\hline \multirow{2}{*}{ Consórcio - $10 \mathrm{~kg} \mathrm{ha}^{-1}$} & $\mathrm{~S}$ & $5,00^{\mathrm{ns}}$ & $3,78^{\mathrm{ns}}$ & $17,33^{\mathrm{ns}}$ & $24,48^{\mathrm{ns}}$ & $5,75^{\text {ns }}$ & $41,15^{\mathrm{ns}}$ & $18,00^{\mathrm{ns}}$ & $1.103,86^{\mathrm{ns}}$ \\
\hline & $\mathrm{C}$ & 7,33 & 2,58 & 14,67 & 20,84 & 5,83 & 42,27 & 18,47 & 978,85 \\
\hline \multirow{2}{*}{ Consórcio - 12,5 kg ha-1 } & $\mathrm{S}$ & 7,00 & 3,52 & 15,67 & 20,75 & 5,37 & 41,23 & 16,70 & 953,08 \\
\hline & $\mathrm{C}$ & 7,00 & 3,97 & 25,17 & 24,83 & 5,00 & 38,50 & 19,24 & $1.148,42$ \\
\hline \multirow{2}{*}{ Consórcio - $15 \mathrm{~kg} \mathrm{ha}^{-1}$} & $S$ & 7,00 & 1,86 & 17,33 & 23,50 & 4,80 & 36,53 & 19,55 & 981,26 \\
\hline & $\mathrm{C}$ & 8,00 & 7,54 & 20,33 & 23,46 & 6,20 & 46,57 & 19,32 & 914,87 \\
\hline Milho Solteiro & & 7,00 & 5,79 & 12,17 & 17,36 & 5,65 & 39,73 & 19,25 & 918,48 \\
\hline $\mathrm{CV}(\%)$ & & 35,72 & 54,22 & 41,67 & 54,16 & 27,98 & 22,85 & 5,69 & 14,34 \\
\hline \multicolumn{10}{|l|}{ Herbicida-caupi } \\
\hline Sem herbicida & & $12,57 \mathrm{a}$ & $7,95 \mathrm{a}$ & $28,10 \mathrm{a}$ & $41,08 \mathrm{a}$ & $5,45^{\mathrm{ns}}$ & $39,46^{\mathrm{ns}}$ & $18,54^{\mathrm{ns}}$ & $978,65^{\mathrm{ns}}$ \\
\hline [imazamoxi+bentazon] + fluazifope & & $1,24 \mathrm{~b}$ & $0,34 \mathrm{~b}$ & $6,95 \mathrm{~b}$ & $3,27 \mathrm{~b}$ & 5,58 & 42,25 & 18,75 & $1.021,01$ \\
\hline $\mathrm{CV}(\%)$ & & 39,66 & 57,95 & 32,18 & 49,60 & 29,23 & 26,58 & 10,03 & 16,45 \\
\hline
\end{tabular}

a/ $\mathrm{e}^{\mathrm{b} /}$ - avaliações feitas aos 25 dias após a aplicação dos herbicidas em pós-emergência do feijão caupi e na colheita, respectivamente. ns - não significativo pelo teste $\mathrm{F}(\mathrm{p}>0,05) .{ }^{1}$ Médias seguidas pelas mesmas letras são estatisticamente iguais pelo teste de Tukey ( $\mathrm{p}>0,05)$, S- sem glifosato, C- com glifosato.

Fonte: Autores (2021).

\section{Conclusão}

O sistema de consórcio, independente das taxas de semeadura da U. ruziziensis ou do seu manejo com glifosato, contribui para a redução da infestação de plantas daninhas.

O uso de glifosato reduziu a produção de palhada de $U$. ruziziensis. 
A produção de grãos das culturas de milho e feijão-caupi não foram afetadas pelos tratamentos testados.

\section{Agradecimentos}

Ao Instituto Federal Goiano, Campus Rio Verde, pelo apoio financeiro.

\section{Referências}

Chioderoli, C. A., de Mello, L. M., Grigolli, P. J., Silva, J. O. D. R., \& Cesarin, A. L. (2010). Consorciação de braquiárias com milho outonal em plantio direto sob pivô central. Engenharia Agrícola, 30(6), 1101-1109. doi: 10.1590/S0100-69162010000600011.

Chioderoli, C. A., Mello, L. M. M. D., Holanda, H. V. D., Furlani, C. E. A., Grigolli, P. J., Silva, J. O. D. R., \& Cesarin, A. L. (2012). Consórcio de Urochloas com milho em sistema plantio direto. Ciência Rural, 42(10), 1804-1810. doi:10.1590/S0103-84782012005000073.

Conab- Companhia Nacional de Abastecimento. Acompanhamento da Safra Brasileira: 10 Levantamento de grãos. Safra 2020. Brasília: Conab, 2019/20, v. 7, n. $10,74 \mathrm{p}$

Gimenes, M. J., Prado, E. P., Ferreira do Amaral Dal Pogetto, M. H., \& de Almeida Costa, S. Í. (2011). Interferência da Brachiaria decumbens Stapf. sobre plantas daninhas em sistema de consórcio com o milho. Revista Caatinga, 24, 215-220. Retrieved from https://periodicos.ufersa.edu.br/index.php/caatinga/article/view/2287/4769

da Silva Araújo, L., da Silva Branquinho, J. A., da Silveira, P. M., Silva, L. G. B., Valente, M. S., de Siqueira, M. V. R., \& da Cunha, P. C. R. (2018). Produtividade de milho solteiro e consorciado com Urochloa brizantha em dois espaçamentos de plantio no sudeste de Goiás. Agrarian, 11(42), 307-318. doi:10.30612/agrarian.v11i42.4335.

Gazziero, D., Adegas, F., Silva, A., \& Concenço, G. (2019). Estimativas de perdas de rendimento na soja devido à interferência do capim-amargoso. Planta Daninha, 37, e019190835. Retrieved from https://doi.org/10.1590/s0100-83582019370100047.

Krenchinski, F. H., Cesco, V. J. S., Castro, E. B., Carbonari, C. A., \& Velini, E. D. (2019). Ammonium glufosinate associated with post-emergence herbicides in corn with the cp4-epsps and pat genes. Planta Daninha, 37, e019184453. doi:10.1590/s0100-83582019370100042.

Lemaire, G., Franzluebbers, A., de Faccio Carvalho, P. C., \& Dedieu, B. (2014). Integrated crop-livestock systems: Strategies to achieve synergy between agricultural production and environmental quality. Agriculture, Ecosystems \& Environment, 190, 4-8. doi:10.1016/j.agee.2013.08.009.

Lima, S. F., Timossi, P. C., Almeida, D. P., \& da Silva, U. R. (2014). Fitossociologia de plantas daninhas em convivência com plantas de cobertura. Revista Caatinga, 27(2), 37-47. Retrieved from https://periodicos.ufersa.edu.br/index.php/caatinga/article/view/3353/pdf_112.

Martins, D., Triguero, L. R. C., Domingos, V. D., Martins, C. C., Marchi, S. R. D., \& Costa, N. V. D. (2007). Seletividade de herbicidas aplicados em pósemergência sobre capim-braquiária. Revista Brasileira de Zootecnia, 36(6), 1969-1974. doi:10.1590/S1516-35982007000900004.

Martha Júnior, G. B., Alves, E., \& Contini, E. (2011). Dimensão econômica de sistemas de integração lavoura-pecuária. Pesquisa Agropecuária Brasileira, 46(10), 1117-1126. doi:10.1590/S0100-204X2011001000002.

Mechi, I. A., dos Santos, A. L. F., Ribeiro, L. M., \& Ceccon, G. (2018). Infestação de plantas daninhas de difícil controle em função de anos de consórcio milho-braquiária. Journal of Neotropical Agriculture, 5(3), 49-54. doi:10.32404/rean.v5i3.1642.

de Mesquita, H. C., de Freitas, F. C. L., Freire Filho, F. R., da Silva, M. G. O., Cunha, J. L. X. L., \& dos Santos Rodrigues, A. P. M. (2017). Eficácia e seletividade de herbicidas em cultivares de feijão-caupi. Revista Brasileira de Herbicidas, 16(1), 50-59. doi:10.7824/rbh.v16i1.505.

de Moraes, A., de Faccio Carvalho, P. C., Anghinoni, I., Lustosa, S. B. C., de Andrade, S. E. V. G., \& Kunrath, T. R. (2014). Integrated crop-livestock systems in the Brazilian subtropics. European Journal of Agronomy, 57, 4-9. doi:10.1016/j.eja.2013.10.004.

Pariz, C. M., Costa, C., Crusciol, C. A., Castilhos, A. M., Meirelles, P. R., Roça, R. O., \& Franzluebbers, A. J. (2017). Lamb production responses to grass grazing in a companion crop system with corn silage and oversowing of yellow oat in a tropical region. Agricultural Systems, 151, 1-11. doi:10.1016/j.agsy.2016.11.004

Pereira, A. S., Shitsuka, D.M., Parreira, F. J., \& Shitsuka, R. (2018). Metodologia da pesquisa científica. 1. ed. - Santa Maria, RS: UFSM, NTE.

Portes, T. D. A., Carvalho, S. I. C. D., Oliveira, I. P. D., \& Kluthcouski, J. (2000). Análise do crescimento de uma cultivar de braquiária em cultivo solteiro e consorciado com cereais. Pesquisa Agropecuária Brasileira, 35(7), 1349-1358. doi:10.1590/S0100-204X2000000700009.

Silva, A. A.; Jakelaitis. A.; Ferreira, L. R. (2004). Manejo de plantas daninhas no sistema integrado agricultura-pecuária. In: Zambolim, L.; Ferreira, A. A.; Agnes, E. L. (Eds.). Manejo integrado: integração agricultura-pecuária. Viçosa, MG: Universidade Federal de Viçosa, $117-169$.

da Silva, A., de Sousa Santos, F. L., de Mattos Barretto, V. C., de Freitas, R. J., \& Kluthcouski, J. (2018). Recuperação de pastagem degradada pelo consórcio de milho, Urochloa brizantha cv. Marandu e guandu. Journal of Neotropical Agriculture, 5(2), 39-47. doi:10.32404/rean.v5i2.1382.

Silva, D. V., Pereira, G. A. M., Freitas, M. A. M. D., Silva, A. A. D., Sediyama, T., Silva, G. S., \& Cecon, P. R. (2015). Produtividade e teor de nutrientes do milho em consórcio com braquiária. Ciência Rural, 45(8), 1394-1400. doi:10.1590/0103-8478cr20140760.

da Silva, J. A., \& Neves, J. A. (2011). Produção de feijão-caupi semi-prostrado em cultivos de sequeiro e irrigado. Revista Brasileira de Ciências Agrárias, 6(1), 29-36. doi:10.5039/agraria.v6i1a748. 